\title{
Successful use of eculizumab in an 86-year-old patient with paroxysmal nocturnal hemoglobinuria in Japan
}

\author{
Yokiko Ooe ${ }^{1 *}$ and Tomoko Nagai ${ }^{2}$
}

\begin{abstract}
Eculizumab was used to treat an 86-year-old male patient with paroxysmal nocturnal hemoglobinuria, the oldest reported case in Japan. As observed in younger patients, this drug rapidly suppressed hemolysis in the present patient, which allowed weaning from blood transfusion. Eculizumab treatment has been continued for 2 years and resulted in the alleviation of renal dysfunction. Despite the patient's advanced age, the inhibition of complement activity caused by this drug did not result in infection, indicating that it is safe to use in elderly patients.
\end{abstract}

Keywords: Renal function; Oldest Japanese patient; Paroxysmal nocturnal hemoglobinuria; Eculizumab

\section{Background}

The complement regulatory proteins CD55 and CD59 bind to glycosylphosphatidylinositol (GPI) on red blood cell membranes and inhibit complement activity, thus preventing hemolysis. Paroxysmal nocturnal hemoglobinuria $(\mathrm{PNH})$ is a disease that involves hemolysis caused by the lack of CD55- or CD59-mediated complement activity inhibition in the absence of GPI anchor on the surface of red blood cells. This occurs in individuals with a defective phosphatidylinositol glycan class A enzyme that prevents normal GPI anchor synthesis (Takahashi et al. 1993). PNH is a very rare disease that develops in approximately 16 per 1 million people, and its onset does not exhibit any age specificity (Hillmen et al. 1995; Nishimura et al. 2004). Hemoglobin release into the bloodstream as a result of hemolysis could lead to massive nitrogen oxide (NO) scavenging in blood vessels; this increases platelet reactivity and aggregation, possibly inducing pulmonary hypertension and/or thrombosis. Hemolysis can also lead to several disorders including renal dysfunction due to massive hemosiderin deposition in the proximal renal tubules. The immune systems of elderly patients are generally compromised compared with those of younger patients (Naylor et al. 2005; Czesnikiewicz-Guzik et al. 2008). However,

\footnotetext{
* Correspondence: yoki@uegahara.net

1Jutoku-kai Uegahara Hospital, 1-85 10 ban-cho Uegahara, Nishinomiya city, Hyogo 662-0884, Japan

Full list of author information is available at the end of the article
}

whether elderly patients with $\mathrm{PNH}$ can be safely treated using medicines that inhibit complement activity remains unknown.

We recently encountered a rare case of $\mathrm{PNH}$ diagnosed at the age of 81 years, in which eculizumab treatment was initiated at the age of 84 years. The details of the clinical course of this patient are presented herein.

\section{Case description}

A 84-year-old man was diagnosed with anemia at a local facility in March 2009 and referred to a specialist. Upon examination at the facility, the patient was conscious, and his palpebral conjunctiva exhibited signs of anemia but no yellowing. His skin showed signs of anemia, but no purpura was detected. No superficial lymph nodes were palpable. No swelling of the liver or spleen, or significant heart or lung disorder was observed. The hematological test results were as follows: red blood cell (RBC) count, $241 \times 10^{4} / \mu \mathrm{L}$; hemoglobin $(\mathrm{Hb}), 8.4 \mathrm{~g} / \mathrm{dL}$; hematocrit, 26\%; reticulocytes, 3.1\%; and white blood cell (WBC) count, 3,370/ $\mu \mathrm{L}$ (48.3\% neutrophils, $41.2 \%$ lymphocytes, and $3.8 \%$ eosinophils). The biochemical test results were as follows: lactate dehydrogenase (LDH), 1,073 U/L; aspartate aminotransferase (AST), $54 \mathrm{U} / \mathrm{L}$; serum creatinine $(\mathrm{sCr}), 1.49 \mathrm{mg} / \mathrm{dL}$; blood urea nitrogen, $15 \mathrm{mg} / \mathrm{dL}$; vitamin $\mathrm{B} 12$, >1,500 pg/mL; haptoglobin, $<10 \mathrm{mg} / \mathrm{dL}$; and direct Coombs test result, negative (Table 1). 
Table 1 Laboratory findings on diagnosis (March 6, 2009)

\begin{tabular}{llll}
\hline Hematology & \multicolumn{3}{l}{ Biochemistry } \\
\hline RBC & $241 \times 10^{4} / \mu \mathrm{L}$ & T-Bil & $1.0 \mathrm{mg} / \mathrm{dL}$ \\
$\mathrm{Hb}$ & $8.4 \mathrm{~g} / \mathrm{dL}$ & AST & $54 \mathrm{U} / \mathrm{L}$ \\
$\mathrm{Ht}$ & $26 \%$ & $\mathrm{ALT}$ & $16 \mathrm{U} / \mathrm{L}$ \\
$\mathrm{MCV}$ & $107.9 \mathrm{Fl}$ & $\mathrm{LDH}$ & $1,073 \mathrm{U} / \mathrm{L}$ \\
$\mathrm{MCH}$ & $34.9 \mathrm{pg}$ & $\mathrm{ALP}$ & $221 \mathrm{U} / \mathrm{L}$ \\
MCHC & $32.3 \mathrm{~g} / \mathrm{dL}$ & $\mathrm{BUN}$ & $15 \mathrm{mg} / \mathrm{dL}$ \\
PLT & $12.6 \times 10^{4} / \mu \mathrm{L}$ & $\mathrm{CRE}$ & $1.49 \mathrm{mg} / \mathrm{dL}$ \\
Reticulocyte & $3.1 \%$ & $\mathrm{CRP}$ & $<0.1 \mathrm{mg} / \mathrm{dL}$ \\
WBC & $3,370 / \mu \mathrm{L}$ & Fe & $76 \mu \mathrm{g} / \mathrm{dL}$ \\
$\quad$ Stab & $0.0 \%$ & $\mathrm{UIBC}$ & $127 \mu \mathrm{g} / \mathrm{dL}$ \\
Seg & $48.3 \%$ & & \\
Eosino & $3.8 \%$ & & \\
Baso & $0.6 \%$ & & \\
Mono & $3.8 \%$ & & \\
Lympho & $41.2 \%$ & & \\
E-bl & $0.5 \%$ & & \\
\hline
\end{tabular}

Bone marrow aspiration in April 2009 demonstrated hypercellular marrow: nuclear cell count (NCC), $21.3 \times$ $10^{4} / \mathrm{mm}^{3}$; megakaryocytes (MgK), $53 / \mathrm{mm}^{3}$ with bilineage dysplasia (i.e., peroxidase-negative myeloid cells, mononuclear megakaryocytes, and increased total erythroblasts [58.8\%]). Chromosome analysis revealed a karyotype of $45 \mathrm{X}-\mathrm{Y}(4) / 46 \mathrm{XY}(16)$. Therefore, the patient was diagnosed with myelodysplastic syndrome (MDS), i.e., refractory cytopenia with multilineage dysplasia. His anemia gradually progressed, and he occasionally required blood transfusion.

In November 2010, the patient's urine output exhibited a cola color. Flow cytometric analysis of red blood cells at the time revealed $1.31 \%$ CD55(-) cells and $49.1 \%$ CD59(-) cells, prompting a diagnosis of PNH (Figure 1). In January 2011, infectious enteritis triggered hemolysis, which warranted blood transfusion. Oral treatment with methenolone $15 \mathrm{mg} /$ day and prednisolone $10 \mathrm{mg} /$ day was subsequently initiated, alleviating the patient's dependence on blood transfusion. However, his hemolysis continued, and renal function gradually deteriorated; estimated glomerular filtration rate (eGFR) decreased from $35.9 \mathrm{~mL} \cdot \mathrm{min}^{-1} \cdot 1.73 \mathrm{~m}^{-2}$ at the patient's first visit to $25.2 \mathrm{~mL} \cdot \mathrm{min}^{-1} \cdot 1.73 \mathrm{~m}^{-2}$. Therefore, eculizumab treatment was initiated in November 2011. Meningococcus vaccine was administered 2 weeks before eculizumab intervention.

Hematological tests performed immediately before eculizumab treatment initiation yielded the following results: RBC, $280 \times 10^{4} / \mu \mathrm{L} ; \mathrm{Hb}, 10.0 \mathrm{~g} / \mathrm{dL}$; and reticulocytes, $4.1 \%$. The biochemical test results were as follows: $\mathrm{LDH}, 1,748 \mathrm{U} / \mathrm{L}$; and total bilirubin, $2.4 \mathrm{mg} / \mathrm{dL}$.

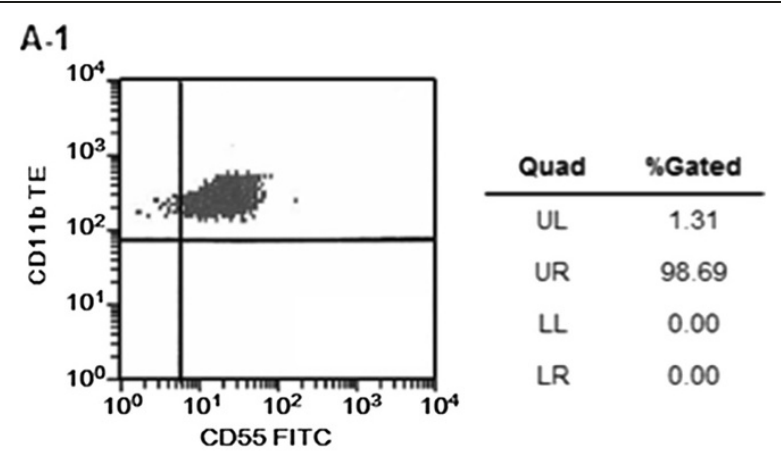

A.2

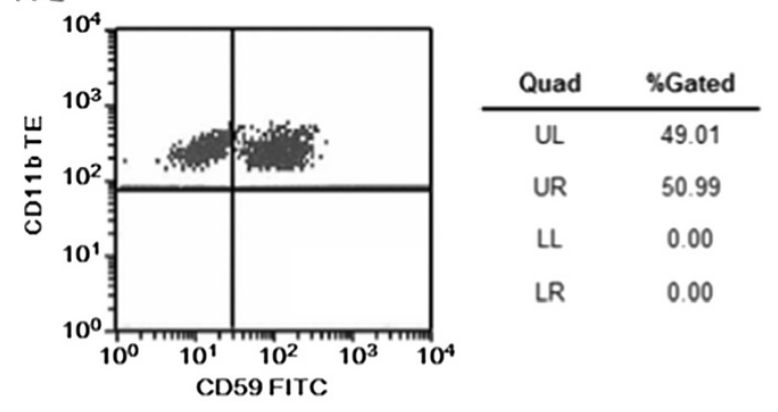

B

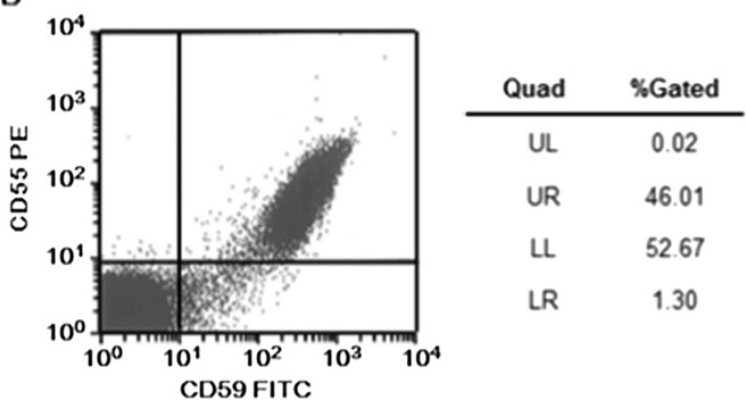

Figure 1 Flow cytometry of red blood cells. A-1: CD55 (pre-eculizumab). A-2: CD59 (pre-eculizumab). B: CD55/CD59 (post-eculizumab).

Eculizumab treatment rapidly reduced LDH levels, which returned to normal (i.e., 234 U/L) 4 weeks after treatment initiation and remained normal thereafter (Figure 2). In February 2012, the percentages of CD55(-) and CD59(-) cells increased to $53.97 \%$ and $47.31 \%$, respectively (Figure 1). Ten months after eculizumab administration, the patient suddenly developed symptoms of anemia, which necessitated blood transfusion. However, this episode was not caused by $\mathrm{PNH}$-induced hemolysis but rather by a bleeding ulcer from the remaining part of the stomach after previous gastric cancer surgery. The ulcer healed in response to fasting and treatment with a proton pump inhibitor and did not trigger a hemolytic attack. No infection-associated adverse events occurred.

Blood transfusion was no longer required thereafter. The patient experienced persistent suppression of hemolysis 

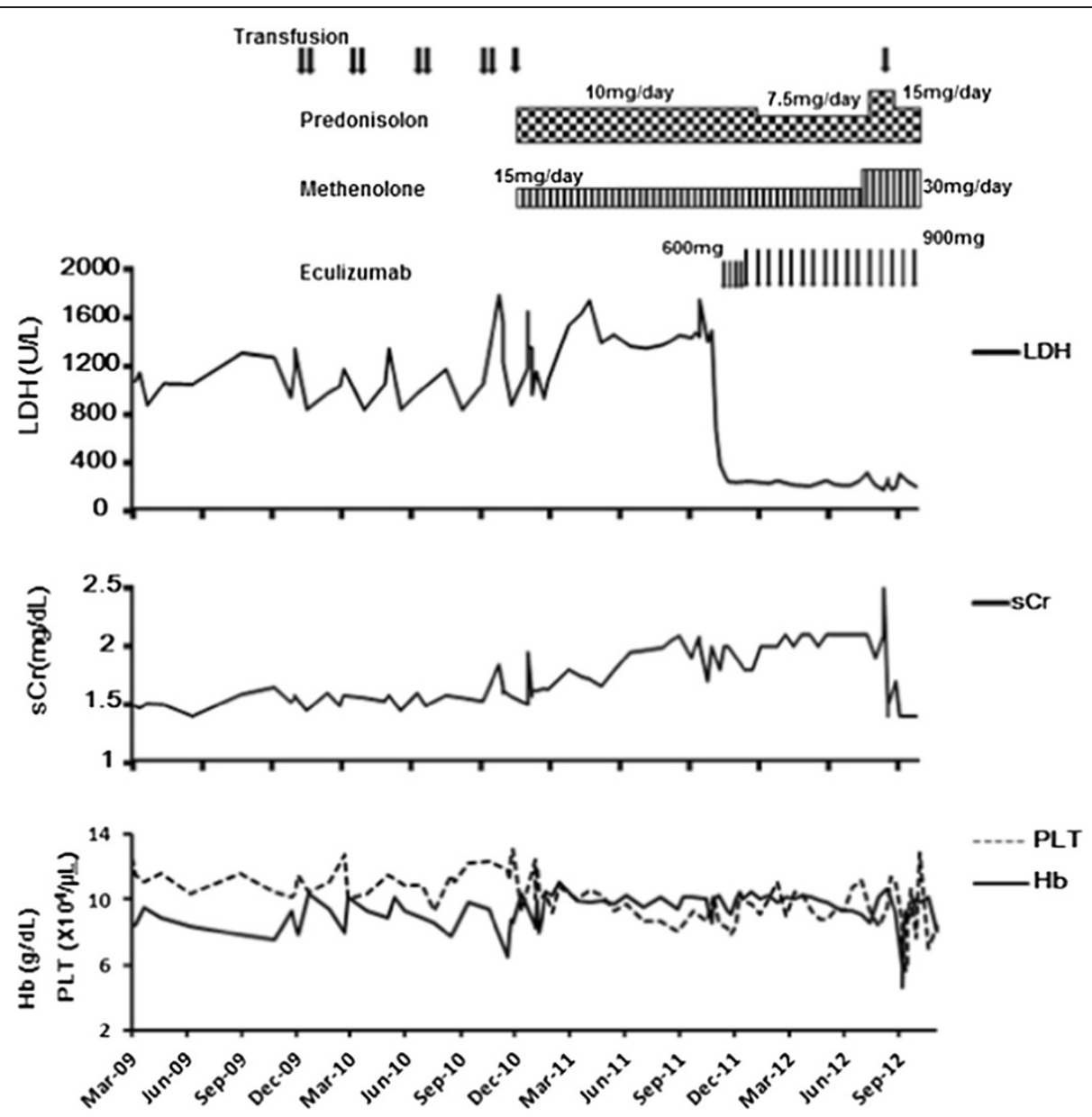

Figure 2 Clinical changes observed in the patient.

and renal function recovery, with $\mathrm{sCr}$ levels decreasing from $2.0 \mathrm{mg} / \mathrm{dL}$ (eGFR, $25.4 \mathrm{~mL} \cdot \mathrm{min}^{-1} .1 .73 \mathrm{~m}^{-2}$ ) to $1.4 \mathrm{mg} / \mathrm{dL}\left(\mathrm{eGFR}, 37.5 \mathrm{~mL} \cdot \mathrm{min}^{-1} \cdot 1.73 \mathrm{~m}^{-2}\right.$ ).

\section{Discussion and evaluation}

Patients with PNH associated with hemolysis are known to present with symptoms including abdominal pain, dysphagia, and pulmonary hypertension due to excessive NO scavenging by hemoglobin released into the blood or thrombosis at various sites as a result of stimulated platelet aggregation (Hill et al. 2010; Rother et al. 2005). Anemia secondary to hemolysis used to be treated with blood transfusion, steroids, or the anticoagulant warfarin (Parker et al. 2005; Hillmen et al. 2007). However, the use of eculizumab, which specifically inhibits complement C5, was approved in Japan in 2010. The complement regulatory proteins CD55 and CD59 play roles in hemolysis prevention. While CD55 regulates the first half of the complement activation pathway by stimulating the destruction of the $\mathrm{C} 3 / \mathrm{C} 5$ converting enzyme, CD59 acts on C9 and inhibits the formation of the membrane attack complex (Nicholson-Weller et al. 1981; Sugita et al. 1988; Davies et al. 1989). When the present patient was diagnosed with $\mathrm{PNH}$, the percentages of CD55(-) and CD59(-) cells were $1.31 \%$ and $49.1 \%$, respectively. The sensitivity of the complement system increases particularly when CD59 is defective; this can lead to the hemolysis of PNH-affected blood cells. Therefore, this mechanism likely led to $\mathrm{PNH}$ development in the present case despite the lower percentage of CD55negative cells detected. Eculizumab reduces LDH levels soon after treatment initiation (Hillmen et al. 2007). Furthermore, as hemolysis is alleviated by this drug, $\mathrm{Hb}$ levels gradually increase (Hillmen et al. 2007; Kanakura et al. 2011). The present patient was initially diagnosed with MDS and exhibited increased WBC counts in response to treatment with methenolone and prednisolone. However, because compromised renal function was still observed, the possibility of $\mathrm{PNH}$-induced chronic renal failure and a subsequent poor prognosis was considered. Therefore, treatment with eculizumab was initiated. Compromised renal function is relatively frequent in 
patients with PNH. In the AEGIS Study, an indication study in Japan, as much as $66 \%$ of the patients studied were associated with abnormal renal function. Another study reports that $18 \%$ of Japanese patients with $\mathrm{PNH}$ died from renal failure (Nishimura et al. 2004). Furthermore, Japanese and global studies demonstrate improved renal function in $30-40 \%$ of all patients receiving prolonged eculizumab treatment (Kanakura et al. 2011; Hillmen et al. 2010). Therefore, eculizumab treatment could be effective for patients with $\mathrm{PNH}$ and compromised renal function.

In the present case, the LDH level immediately prior to treatment initiation was $1,491 \mathrm{U} / \mathrm{L}$; it started decreasing soon after eculizumab treatment initiation, returning to normal (i.e., 234 U/L) 4 weeks later. Eculizumab protects red blood cells that lack CD55 or CD59 (also known as "PNH-type red blood cells") from hemolysis, resulting in higher percentages of $\mathrm{PNH}$-type red blood cells in patients with PNH (Hillmen et al. 2010). In fact, high percentages of PNH-type red blood cells were observed in the present patient after eculizumab treatment (54\% and $47 \%$ of CD55(-) and CD59(-) cells, respectively). This suggests that PNH-type red blood cells survived and did not undergo hemolytic destruction.

In view of age-associated reduction in immune function and the effect of eculizumab on the suppression of the terminal complement pathway (i.e., C5 and subsequent components), one concern is that treatment with eculizumab may elevate the risk of infection in elderly patients (Naylor et al. 2005; Czesnikiewicz-Guzik et al. 2008). Indication studies of eculizumab have been performed globally including Japan. However, because of the nature of these studies, patients aged $>80$ years were rarely enrolled; the oldest patient enrolled in Japan was aged 70 years. The major adverse events observed in that study were headache (52\%), nasopharyngitis (41\%), nausea $(21 \%)$, and diarrhea (13\%); however, no infectious adverse events possibly associated with eculizumab treatment were reported (Hillmen et al. 2010). The present patient was diagnosed with $\mathrm{PNH}$ at the age of 81 years and began receiving eculizumab treatment at the age of 84 years. This is a rare case of an elderly patient treated with eculizumab. Moreover, the renal function of this patient improved from CKD stage 4 to stage 3 during eculizumab treatment.

\section{Conclusions}

Our experience with the present case indicates that even patients aged $>80$ years with compromised renal function can be safely treated with eculizumab. The findings of this case suggest that eculizumab treatment is effective and useful for improving renal function, facilitating weaning from blood transfusion, and alleviating $\mathrm{PNH}$ patients' fear of experiencing a hemolytic attack.

\section{Abbreviations}

GPI: Glycosylphosphatidylinositol; PNH: Paroxysmal nocturnal hemoglobinuria; NO: Nitrogen oxide; RBC: Red blood cell; Hb: Hemoglobin; WBC: White blood cell; LDH: Lactate dehydrogenase; AST: Aspartate aminotransferase; sCr: Serum creatinine; NCC: Nuclear cell count; MgK: Megakaryocytes; MDS: Myelodysplastic syndrome; eGFR: Estimated glomerular filtration rate; CKD: Chronic kidney disease.

\section{Competing interests}

The authors declare that they have no conflict of interest.

\section{Authors' contributions}

$\mathrm{YO}$ is currently treating the patient. TN initially treated the patient and referred him to YO for eculizumab intervention. The clinical data of the patient were gathered by both authors. YO drafted, edited, and revised the manuscript after review by TN. Both authors read and approved the final manuscript.

\section{Author details}

1Jutoku-kai Uegahara Hospital, 1-85 10 ban-cho Uegahara, Nishinomiya city, Hyogo 662-0884, Japan. ${ }^{2}$ Department of Hematology, Hyogo Prefectural Tsukaguchi Hospital, 6-17 6-chome Minami-tsukaguchi-cho, Amagasaki city, Hyogo 661-0012, Japan.

Received: 13 August 2013 Accepted: 2 December 2013

Published: 4 January 2014

\section{References}

Czesnikiewicz-Guzik M, Lee WW, Cui D, Hiruma Y, Lamar DL, Yang ZZ, Ouslander JG, Weyand CM, Goronzy J (2008) T cell subset-specific susceptibility to aging. Clin Immunol 127:107-118

Davies A, Simmons DL, Hale G, Harrison RA, Tighe H, Lachmann PJ, Waldmann H (1989) CD59, an LY-6-like protein expressed in human lymphoid cells, regulates the action of the complement membrane attack complex on homologous cells. J Exp Med 170:637-654

Hill A, Rother RP, Wang X, Morris SM Jr, Quinn-Senger K, Kelly R, Richards SJ, Bessler M, Bell L, Hillmen P, Gladwin MT (2010) Effect of eculizumab on haemolysis-associated nitric oxide depletion, dyspnoea, and measures of pulmonary hypertension in patients with paroxysmal nocturnal haemoglobinuria. Br J Haematol 149:414-425

Hillmen P, Lewis SM, Bessler M, Luzzatto L, Dacie JV (1995) Natural history of paroxysmal nocturnal hemoglobinuria. N Engl J Med 333:1253-1258

Hillmen P, Muus P, Dührsen U, Risitano AM, Schubert J, Luzzatto L, Schrezenmeier H, Szer J, Brodsky RA, Hill A, Socié G, Bessler M, Rollins SA, Bell L, Rother RP, Young NS (2007) Effect of the complement inhibitor eculizumab on thromboembolism in patients with paroxysmal nocturnal hemoglobinuria. Blood 110:4123-4128

Hillmen P, Elebute M, Kelly R, Urbano-Ispizua A, Hill A, Rother RP, Khursigara G, Fu CL Omine M, Browne P, Rosse W (2010) Long-term effect of the complement inhibitor eculizumab on kidney function in patients with paroxysmal nocturnal hemoglobinuria. Am J Hematol 85:553-559

Kanakura Y, Ohyashiki K, Shichishima T, Okamoto S, Ando K, Ninomiya H, Kawaguchi T, Nakao S, Nakakuma H, Nishimura J, Kinoshita T, Bedrosian CL, Valentine ME, Khursigara G, Ozawa K, Omine M (2011) Safety and efficacy of the terminal complement inhibitor eculizumab in Japanese patients with paroxysmal nocturnal hemoglobinuria: the AEGIS clinical trial. Int J Hematol 93:36-46

Naylor K, Li G, Vallejo AN, Lee WW, Koetz K, Bryl E, Witkowski J, Fulbright J, Weyand CM, Goronzy JJ (2005) The influence of age on T cell generation and TCR diversity. J Immunol 174:7446-7452

Nicholson-Weller A, Burge J, Austen KF (1981) Purification from guinea pig erythrocyte stroma of a decay-accelerating factor for the classical c3 convertase, C4b,2a. J Immunol 127:2035-2039

Nishimura J, Kanakura Y, Ware RE, Shichishima T, Nakakuma H, Ninomiya H, Decastro CM, Hall S, Kanamaru A, Sullivan KM, Mizoguchi H, Omine M, Kinoshita T, Rosse WF (2004) Clinical course and flow cytometric analysis of paroxysmal nocturnal hemoglobinuria in the United States and Japan. Medicine 83:193-207

Parker C, Omine M, Richards S, Nishimura J, Bessler M, Ware R, Hillmen P, Luzzatto L, Young N, Kinoshita T, Rosse W, Socié G (2005) Diagnosis and management of paroxysmal nocturnal hemoglobinuria. Blood 106:3699-3709 
Rother RP, Bell L, Hillmen P, Gladwin MT (2005) The clinical sequelae of intravascular hemolysis and extracellular plasma hemoglobin: a novel mechanism of human disease. JAMA 293:1653-1662

Sugita Y, Nakano Y, Tomita M (1988) Isolation from human erythrocytes of a new membrane protein which inhibits the formation of complement transmembrane channels. J Biochem 104:633-637

Takahashi M, Takeda J, Hirose S, Hyman R, Inoue N, Miyata T (1993) Deficient biosynthesis of $\mathrm{N}$-acetylglucosaminyl-phosphatidylinositol, the first

intermediate of glycosyl phosphatidylinositol anchor biosynthesis, in cell lines established from patients with paroxysmal nocturnal hemoglobinuria. J Exp Med 177:517-521

doi:10.1186/2193-1801-3-10

Cite this article as: Ooe and Nagai: Successful use of eculizumab in an 86-year-old patient with paroxysmal nocturnal hemoglobinuria in Japan. SpringerPlus 2014 3:10.

\section{Submit your manuscript to a SpringerOpen ${ }^{\circ}$ journal and benefit from:}

- Convenient online submission

- Rigorous peer review

- Immediate publication on acceptance

- Open access: articles freely available online

- High visibility within the field

- Retaining the copyright to your article

Submit your next manuscript at $\gg$ springeropen.com 